\title{
Health-Related Quality of Life of Patients
}

\section{Presenting to the Emergency Department with a Musculoskeletal Disorder}

\author{
Rose Gagnon $\mathbb{D}^{1,2}$, Kadija Perreault ${ }^{1,2}$, Jason R Guertin $\mathbb{D}^{3,4}$, Simon Berthelot $\mathbb{D}^{4-6}$, Bertrand Achou ${ }^{7}$, \\ Luc J Hébert $\mathbb{D}^{1,2,8}$
}

'Centre for Interdisciplinary Research in Rehabilitation and Social Integration (Cirris), Centre intégré universitaire de santé et de services sociaux (CIUSSS) de La Capitale-Nationale, Quebec City, Quebec, Canada; ${ }^{2}$ Department of Rehabilitation, Université Laval, Quebec City, Quebec, Canada; ${ }^{3}$ Department of Social and Preventive Medicine, Université Laval, Quebec City, Quebec, Canada; ${ }^{4}$ Centre de recherche du CHU de Québec Université Laval, Quebec City, Quebec, Canada; ${ }^{5}$ Department of Family Medicine and Emergency Medicine, Université Laval, Quebec City, Quebec, Canada; ${ }^{6} \mathrm{CHU}$ de Québec - Université Laval, Quebec City, Quebec, Canada; ${ }^{7} \mathrm{HEC}$ Montreal, Montreal, Quebec, Canada; ${ }^{8}$ Department of Radiology and Nuclear Medicine, Université Laval, Quebec City, Quebec, Canada

Correspondence: Luc J Hébert, Cirris, CIUSSS de la Capitale-Nationale, 525 Boulevard Wilfrid-Hamel, H-I4I0, Quebec City, Quebec, GIM 2S8, Canada, Tel +| $4 \mid 8$ 529-9|4| ext 6579, Email lucj.hebert@fmed.ulaval.ca

Background: Musculoskeletal disorders (MSKDs) are among the most disabling and costly non-fatal health conditions. They may lead to long-term consequences such as chronic pain, physical limitations, and poorer quality of life. They also account for a significant proportion of emergency department visits, representing between $18 \%$ and $25 \%$ of all visits, depending on country.

Purpose: To assess the health-related quality of life of patients presenting to the emergency department with a MSKD, to convert their answers to utility scores and to explore the association between diverse socio-demographic and clinical variables and patients' health-related quality of life.

Patients and Methods: This is an analysis of cross-sectional data obtained during the baseline assessment performed as part of a 6-month pragmatic randomized controlled trial conducted in an academic emergency department. We included patients aged 18-80 years with a minor MSKD. The main outcome measures were health-related quality of life (five dimensions: mobility, self-care, usual activities, pain/discomfort, and anxiety/depression) and utility scores $(-0.148$ - worse than death, $0-$ dead, $0.949-$ perfect health) measured with the EQ-5D-5L. Possible associations were explored by comparing scores across subgroups based on certain sociodemographic (eg, age, gender, triage score) and clinical factors (eg, pain interference on function, pain intensity) and with reference values using descriptive statistics (mean, median), rankFD ANOVAs, and $\chi^{2}$ tests.

Results: Sixty-nine participants completed the EQ-5D-5L. Mean and median utility scores were, respectively, 0.536 (95\% CI: 0.479-0.594) and 0.531 (IQR: 0.356-0.760). Participants with higher levels of pain (<4/10: 0.741, 95\% CI: 0.501-0.980; 4-7/10: 0.572, 0.500-0.644; >7/10: $0.433,0.347-0.518)$ or pain interference on function (<4/10: $0.685,95 \%$ CI: $0.605-0.764 ; 4-7 / 10: 0.463,0.394-0.533$; >7/10: 0.294, 0.1260.463 ) presented significantly lower utility scores. No significant differences were found for other socio-demographic characteristics.

Conclusion: In patients with MSKDs who present to the emergency department, higher levels of pain or pain interference are associated with decreased health-related quality of life. These findings need to be confirmed on a larger scale.

Keywords: EQ-5D-5L, quality of life, pain, emergency services, musculoskeletal disorders

\section{Introduction}

Musculoskeletal disorders (MSKDs) commonly refer to a group of symptoms and inflammatory or degenerative lesions of the musculoskeletal system in the neck, back, upper or lower limbs. ${ }^{1}$ MSKDs are very common and are associated with various impairments such as pain, stiffness, loss of joint mobility and muscle strength, as well as bone deformity. ${ }^{2}$ They are among the most disabling and costly non-fatal health conditions and their prevalence is expected to increase over the next decade. ${ }^{3-5}$ If not managed promptly, they can have long-term consequences such as increased pain, loss of 
mobility and a greater risk of developing psychological symptoms. ${ }^{6,7}$ Patients presenting a MSKD that are not quickly managed also are more likely to be absent due to illness, experience greater loss of productivity at work, and make greater use of resources within the healthcare system. ${ }^{8-14}$ Currently, around $25 \%$ of all emergency department (ED) visits in several countries are for MSKDs, including the US and Canada. ${ }^{15-19}$

Furthermore, several studies have examined the impact of MSKDs on health-related quality of life. The vast majority of them report that MSKDs can negatively affect patients' daily activities and health-related quality of life. ${ }^{6-8,20,21}$ Indeed, patients with a MSKD report significantly lower health-related quality of life than those without. ${ }^{22-24}$ Compared with other chronic conditions, MSKDs are responsible for the greatest loss in health-related quality of life. ${ }^{25,26}$ However, most studies were conducted in the general population; each individual in the sample was assessed as to whether or not they had a MSKD and subsequently completed one or more quality of life measures. ${ }^{22-24}$ No study has specifically focused on health-related quality of life in persons visiting the ED for a MSKD. A sample derived from the general population differs greatly from a subpopulation sample of MSKD patients presenting to the ED, in that the reasons why people with a MSKD visit the ED include a loss of function, a sense that their current pain is different from their previous pain, and a desire for rapid pain relief, all of which can negatively affect health-related quality of life. ${ }^{27}$ This suggests that the health-related quality of life of these individuals may be lower than that of individuals with a similar disorder in the general population and that specific attention should therefore be paid to the health-related quality of life of this subpopulation.

Several interventions have been developed over time to specifically manage individuals presenting to the ED with a MSKD. ${ }^{15,16,28-36}$ Although some have proven effective (eg, ${ }^{15,16,31,32,36}$ ), very few have specifically measured their impact on the health-related quality of life of these patients, in part because there are currently no baseline values for health-related quality of life in a subpopulation with a MSKD in the ED. Greater knowledge of health-related quality of life in a subpopulation such as this one would better inform research on interventions aiming at optimizing their care. ${ }^{37}$

In another vein, the EQ-5D-5L is a widely used preference-based multi-attribute health status classification system $^{38,39}$ which provides a measure of health-related quality of life (ie, utility score). When compared to a province or country's norms (eg, ${ }^{39-41}$ ), utility scores obtained in a subgroup with a condition such as a MSKD can provide a better understanding of the effects of a particular health condition on health-related quality of life. A better understanding of the utility scores specific to certain disorders and the factors that may affect them could also allow better tailoring and prioritization of services and resources to these patients. ${ }^{41-43}$ Although the EQ-5D-5L is one of the most widely used health-related quality of life measures to date, the majority of utility scores for patients with MSKDs have been published in Europe and very few have been published in North America. Moreover, to our knowledge, no utility scores have been published for MSKD patients in the ED. Such measures would prove useful as low health-related quality of life is associated with an increased risk of repeat visits to the ED. ${ }^{44} \mathrm{~A}$ better understanding of the health-related quality of life of patients when they visit the ED would also allow a better understanding of the factors affecting it, as well as a better prioritization and tailoring of the services and resources offered to them in the ED. ${ }^{41-43}$

A number of studies have looked at factors influencing health-related quality of life in people with MSKDs. For example, health-related quality of life of persons experiencing MSKDs was found to decrease to a greater extent with increasing age. ${ }^{45}$ Sex has been shown to be an important factor in this patient population as well; health-related quality of life was found to be poorer in women than in men with an equivalent MSKD. ${ }^{46}$ Moreover, patients with more than one painful site or more than one MSKD show even lower health-related quality of life than those with only one painful site as they are more likely to report difficulty sleeping, poorer general health, and more difficulties with functional abilities. ${ }^{23,24,45}$ However, although these studies have looked at the influence of certain factors on health-related quality of life in persons with a MSKD, it is difficult to compare quality of life between studies from different countries because utility scores may be affected by differences in the definition of the condition of interest (in this case MSKDs), the study selection process, co-morbidities, the age of the participants, language, and culture. ${ }^{23}$ Some studies have also suggested that triage scores in the ED are associated with some patients' characteristics that might influence health-related quality of life. ${ }^{4-49}$ However, very few studies have focused on factors associated with health-related quality of life in the ED.

Therefore, in order to address the above-mentioned important gaps in current knowledge, this study first aimed to assess the health-related quality of life of patients presenting to the ED with a MSKD using an indirect solicitation 
method (EQ-5D-5L), allowing to convert their answers to utility scores using the Canadian EQ-5D-5L conversion algorithm developed by Xie et al. ${ }^{38}$ The secondary aim was to explore the association between certain socio-demographic and clinical variables and health-related quality of life.

\section{Materials and Methods}

\section{Study Design and Population}

Cross-sectional data were acquired during the baseline assessment performed as part of a single center randomized controlled trial conducted between September 2018 and March 2019 in an Academic ED in Quebec City (Canada). ${ }^{50}$ In this trial, management by a physiotherapist in the ED compared to usual care resulted in a decrease in the level of pain and pain interference on function for up to 3 months post-initial consultation, as well as a reduction in the number of recommended imaging studies, the amount of prescription and non-prescription medication used, and repeat visits to the ED for the same condition. ${ }^{50}$ The study was approved by the Research Ethics Committee of the CHU de Québec Université Laval and registered at the US National Institutes of Health \#NCT04009369. Patients presenting to the ED were recruited if they had a potential peripheral or vertebral minor MSKD (eg, sprain, strain, tendinitis, low back pain, neck pain) and if given a triage score of 3 (urgent), 4 (less urgent) or 5 (non urgent) based on the Canadian Emergency Department Triage and Acuity Scale classification. ${ }^{51}$ Other criteria for inclusion were being aged between 18 and 80 years old, having the ability to legally consent and participate, understanding French to complete the study questionnaires orally or in writing and being a beneficiary of the Quebec provincial health insurance plan (Régie de l'assurance maladie du Québec). The exclusion criteria were to present a major MSKD requiring emergent care (eg, open fracture, dislocation, open wound), a red flag (eg, progressive neurological disorder, infectious symptoms), a concomitant unstable clinical condition (eg, pulmonary, cardiac, digestive and/or psychiatric) or being hospitalized or living in a long-term care facility.

\section{Study Recruitment}

Patients were considered for enrollment in the study (ie, has having a MSKD) based on triage information collected by the ED nurse and included within the electronic information system used at the ED to register patients. The research coordinator (RG) checked any new patient registered in the system to see if they were eligible and consented to participate in the study. Each participant was then asked to provide socio-demographic and clinical data and complete baseline data on pain intensity, pain interference with function and health-related quality of life prior to their consultation with the emergency physician or physiotherapist.

\section{Measures}

Our primary outcome was the health-related quality of life at the ED visit measured using the EQ-5D-5L descriptive system. ${ }^{52}$ The EQ-5D-5L includes five dimensions representing different facets of daily life: mobility, self-care, usual activities, pain/discomfort, and anxiety/depression. These dimensions are scored on five levels ranging from no problem to unable/extreme problem. The EQ-5D-5L allows to derive a health state (ie, 11111 to 55555) which can then be transformed into a measure of health-related quality of life (ie, utility score). The EQ visual analog scale (VAS) ranging from 0 (worst imaginable health state) to 100 (best imaginable health state) was also used. The EQ-5D-5L has been recognized as being reliable, valid and responsive. ${ }^{53,54}$ The questionnaire was administered using paper format in the ED. Health utility scores were calculated using the Canadian value set developed by Xie et al using a composite time trade-off (traditional and lead time trade-off). ${ }^{38}$ Utility scores based on this value set range from -0.148 (55555 - worst health state) to 0.949 (11111 - best health state) depending on the health state reported by the participant with the EQ-5D-5L.

Several demographic and clinical characteristics that might affect health-related quality of life, such as age, gender, triage score, annual income, other health conditions (eg, arthritis or osteoarthritis, heart disease, hypertension, or diabetes), onset and region of the presenting complaint were compiled using the initial questionnaire, as mentioned above. Pain intensity was measured using the Numeric Pain Rating Scale, an 11-point scale ranging from 0 (no pain) to 10 (worst pain imaginable). Pain interference with function was measured using the Pain Inventory subscale of the short version of the Brief Pain Inventory. This subscale covers ten activities of daily living: general activity, mood, walking, 
work, sleep, personal care, etc. For each, the respondent is asked to indicate the extent to which pain experienced in the past 7 days interfered with each of the activities on a scale of 0 to 10 , where 10 means that the pain experienced completely interfered with the activity and 0 that pain does not interfere with activity. Once the 10 items have been rated by the patient, an average out of 10 is performed to obtain a mean score for pain interference on function. Both tools have been shown to be reliable, valid and responsive. ${ }^{55-58}$

\section{Data Analysis}

Socio-demographic, utility and VAS scores were calculated using descriptive statistics (both mean and median scores were produced for utility and VAS scores). We used non-parametric repeated-measures analyses of variance (one-way and two-way rankFD ANOVAs) to compare median utility scores in the different subgroups (R software, 4.0.2; package rankFD, 0.0 .5 ; proc rankFD). $\chi^{2}$ tests were used to compare the distribution of problems reported by dimension and demographic characteristics (SPSS software, version 25; IBM, Armonk, NY, USA). The $\alpha$ criterion was set at 0.05 for all statistical analyses.

We performed subgroup analyses based on age, gender, annual income, self-reported other health conditions, onset of MSKD, presenting complaint, triage score, pain level and pain interference on function to explore the association between these characteristics and health-related quality of life. The sample size was calculated a priori using G*Power software based on the Minimum clinically important difference (MCID) of the Brief Pain Inventory (BPI), a questionnaire that was used in the randomized clinical trial as primary outcome measure (pain interference on function). More information can be found elsewhere. ${ }^{50}$

\section{Results}

\section{Participants}

The eligibility of 589 patients was assessed and 78 were recruited (Figure 1). The EQ-5D-5L was completed by 69 of the $78(88.5 \%)$ participants recruited (Figure 1). Participants who did not complete the questionnaire either forgot it or could not complete it since it was not available during the first week of the randomized trial due to administrative delays. In terms of baseline characteristics, the majority of participants recruited were between 18 and 65 years of age, male, and had an income level considered low to moderate (Table 1). Most participants did not report any associated health condition, had a triage score of 4 (less urgent) and presented a complaint related to the spine or the lower limb. For more than $80 \%$ of all participants, the onset of their condition occurred within the last two weeks (Table 1). Nearly $90 \%$ of the participants had a pain level greater than $4 / 10$ and $50 \%$ of the participants had pain interference with function between 4 and $7 / 10$.

\section{Overall EQ-5D-5L Utility Scores and EQ-VAS Scores}

Table 2 lists all mean and median utility scores according to the demographic and clinical characteristics presented earlier. Mean and median overall health-related utility scores were, respectively, 0.536 (95\% CI: $0.479-0.616)$ and 0.540 (IQR: 0.357-0.782). The mean overall EQ-VAS score was 58.1 (95\% CI: 52.2-64.0). The lowest utility scores were between 0.00 and 0.10 and the highest ones, between 0.90 and 0.949 (Figure 2). Forty-seven percent of participants had a utility score comprised between 0.00 and 0.50 (Figure 2). EQ-VAS scores ranged from 5 to 100 and more than $30.9 \%$ of participants presented a score between 5 and 50 (Figure 3).

\section{Differences in Scores According to Demographic and Clinical Characteristics}

No significant differences were found in subgroup scores as for age, gender, triage score, annual income, presence of a selfreported other health condition, onset and region of the presenting complaint. Participants who reported a higher level of pain during their ED visit had significantly lower utility scores than those with a lower pain level $(\mathrm{p}=0.019$, Table 2). A higher level of pain interference on function was also associated with a significantly lower utility score $(\mathrm{p}=0.001)$.

When considering the five dimensions of the EQ-5D-5L separately, $72.5 \%$ of participants considered having mobility problems, $58.0 \%$ self-care problems, $89.7 \%$ problems with their usual activities, $97.0 \%$ pain or discomfort and $46.4 \%$ 


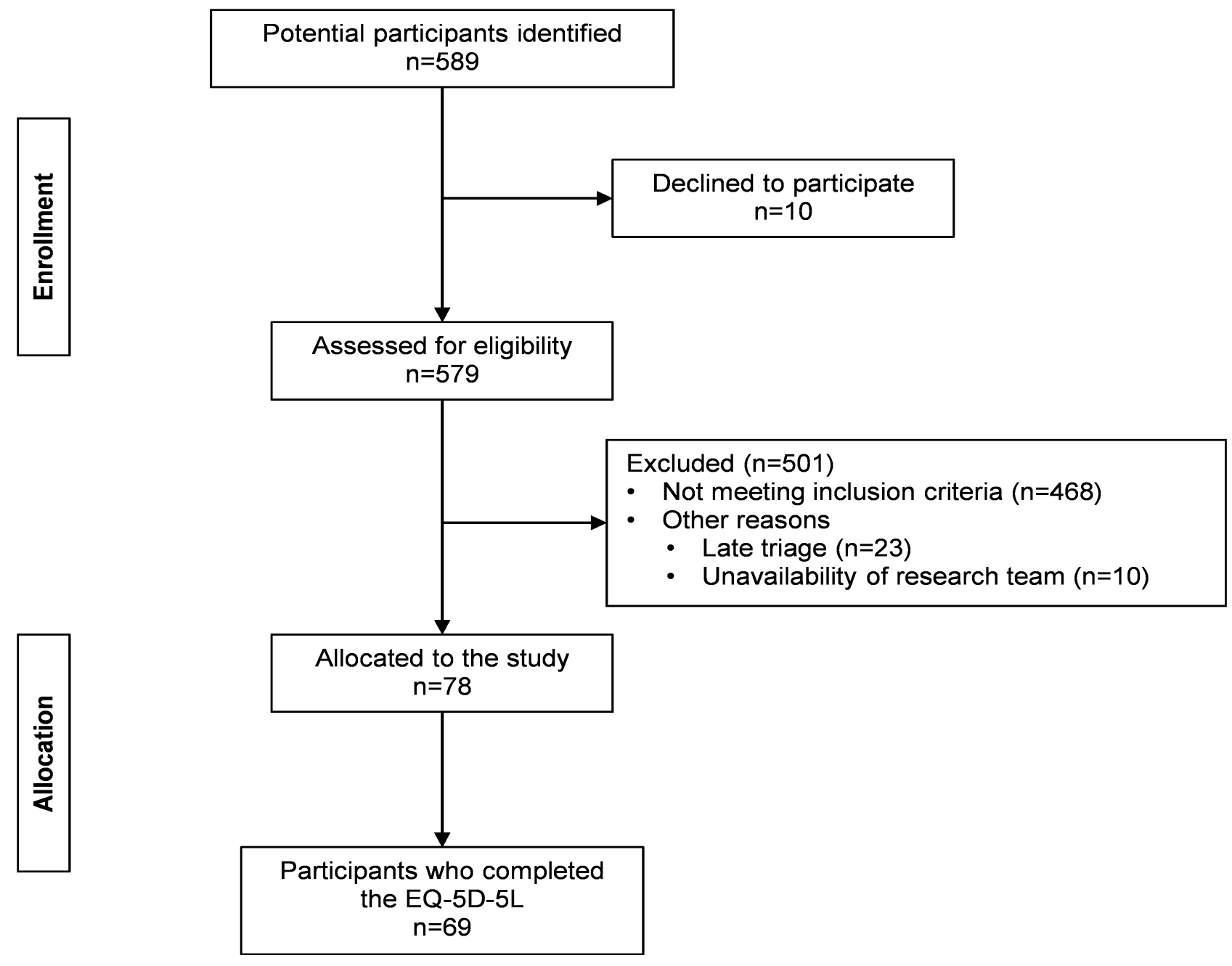

Figure I Participants' recruitment Flowchart.

anxiety or depression (Table 3). No significant differences were found between women and men or between participants with a triage score of 3 or 4 in the distribution of problems reported (Table 3). However, women reported less pain/ discomfort (Pain severe to extreme, Men: 52.6\%, Women: 42.9\%) and more anxiety/depression (Presence of anxiety/ depression, Men: 42.5\%, Women: 51.7\%) than men (Table 3). Participants with a triage score of 3 reported more problems with their usual activities (Severe problems to unable, 3: $50.0 \%, 4: 28.2 \%$ ) and more anxiety or depression (Presence of anxiety/depression, 3: 51.7\%, 4: 43.6\%) (Table 3).

\section{Discussion}

The aim of our study was to assess the health-related quality of life of patients presenting to the ED with a MSKD using an indirect solicitation method (EQ-5D-5L), to convert their answers to utility scores and to explore the association between health-related quality of life and age, gender, triage score, annual income, self-reported other health conditions, onset of MSKD, presenting complaint, pain level and pain interference on function. Participants with higher pain level or pain interference on function reported significantly lower health-related quality of life. No significant differences were found for all other socio-demographic characteristics.

To our knowledge, no EQ-5D-5L utility scores have been published for MSKD patients presenting to the ED. However, Quebec population reference values were published in 2019 by Poder et al. ${ }^{40}$ In their study, the overall mean health-related utility score was 0.824 (95\% CI: 0.818-0.829). Using the EQ-5D-5L minimally important difference (MID: 0.074$)$ as a comparison, this score is clinically higher than the value obtained in our study at 0.536 (95\% CI: 
Table I Baseline Characteristics of Study Participants $(n=69)$

\begin{tabular}{|c|c|c|}
\hline Characteristics & Sample (\%) & $95 \% \mathrm{Cl}(\%)$ \\
\hline \multicolumn{3}{|l|}{ Age, yrs } \\
\hline $18-65$ & 88.4 & $77.9-94.5$ \\
\hline$>65$ & 11.6 & $5.5-22.1$ \\
\hline \multicolumn{3}{|l|}{ Gender } \\
\hline Women & 42.0 & $30.4-54.5$ \\
\hline Men & 58.0 & $45.5-69.6$ \\
\hline \multicolumn{3}{|l|}{ Triage score $^{\mathrm{a}}$} \\
\hline Urgent (P3) & 42.6 & $30.4-54.5$ \\
\hline Semi-Urgent (P4) & 57.4 & $44.1-68.2$ \\
\hline \multicolumn{3}{|l|}{ Gross income, $\$ \mathrm{CAN}^{\mathrm{b}}$} \\
\hline $1-49,999$ & 65.1 & $51.9-76.4$ \\
\hline $50,000-99,999$ & 34.9 & $23.6-48.1$ \\
\hline \multicolumn{3}{|l|}{ Self-reported other health conditions } \\
\hline No & 58.0 & $45.5-69.6$ \\
\hline Yes & 42.0 & $30.4-54.5$ \\
\hline \multicolumn{3}{|l|}{ Onset of MSKD, weeks ${ }^{c}$} \\
\hline $0-2$ & 82.1 & $70.4-90.0$ \\
\hline$>3$ & 17.9 & $10.0-29.6$ \\
\hline \multicolumn{3}{|l|}{ Presenting complaint ${ }^{c}$} \\
\hline Upper limb & 11.9 & $5.7-22.7$ \\
\hline Lower limb & 38.8 & $27.4-51.5$ \\
\hline Cervical spine & 22.4 & $13.5-34.5$ \\
\hline Thoracic and lumbar spine & 26.9 & $17.1-39.3$ \\
\hline \multicolumn{3}{|l|}{ Pain level, $/ 10^{\mathrm{a}}$} \\
\hline$<4$ & 11.2 & $5.6-22.4$ \\
\hline 4 to 7 & 48.5 & $36.4-60.9$ \\
\hline$>7$ & 39.7 & $28.3-52.3$ \\
\hline \multicolumn{3}{|l|}{ Pain interference, / 10} \\
\hline$<4$ & 40.6 & $29.1-53.1$ \\
\hline 4 to 7 & 50.1 & $38.5-62.9$ \\
\hline$>7$ & 8.7 & $3.6-18.6$ \\
\hline
\end{tabular}

Note: ${ }^{a} n=68,{ }^{b}=63,{ }^{c} n=67$.

Abbreviations: Yrs, years; $\mathrm{Cl}$, confidence interval; MSKD, musculoskeletal disorder.

0.479-0.594). ${ }^{59}$ Also, according to Poder et al, ${ }^{40}$ in patients with MSKDs other than osteoarthritis, the mean utility score was 0.586 (95\% CI: 0.546-0.627), which is higher than the score obtained in our study, but not clinically different. Poder et al reported a mean utility score using the EQ-5D-5L of 0.631 (95\% CI: 0.607-0.654) for persons presenting all levels of pain intensity $(\mathrm{n}=367),{ }^{40}$ a number which is clinically higher than the mean utility scores observed in our study. In another study, Poder et al measured health-related quality of life in a Quebec population with chronic low back pain. ${ }^{60}$ In this study, ${ }^{60}$ Poder et al reported a median utility score in relation to today's pain intensity of 0.745 (IQR: $0.616-0.846$ ) for a pain intensity of $0-3 / 10,0.668$ (IQR: $0.411-0.746$ ) for a pain intensity of 4-6/10, and 0.439 (IQR: $0.243-0.660$ ) for a pain intensity of 7-10/10. Though median scores were higher in our patients with a pain intensity of $0-3 / 10(0.867$ [IQR: $0.610-0.882]$ ), results obtained by Poder et al tend to be similar to those obtained in our study. The low scores could be partially explained by the fact that patients consulting the ED for a MSKD are often more concerned about their condition. In fact, certain factors specific to patients, such as having a chronic disease, having already experienced 
Table 2 EQ-5D-5L Utility Scores and EQ-VAS Scores $(n=69)$

\begin{tabular}{|c|c|c|c|c|}
\hline & \multicolumn{4}{|c|}{ EQ-5D-5L } \\
\hline & Mean & $(95 \% \mathrm{Cl})$ & Median & (IQR) \\
\hline Overall & 0.536 & $(0.479-0.594)$ & 0.531 & $(0.356-0.760)$ \\
\hline EQ-VAS & 58.1 & $(52.2-64.0)$ & 60.0 & $(40.0-60.0)$ \\
\hline \multicolumn{5}{|l|}{ Age, years } \\
\hline $18-65$ & 0.554 & $(0.492-0.616)$ & 0.540 & $(0.357-0.782)$ \\
\hline$>65$ & 0.412 & $(0.253-0.57 I)$ & 0.443 & $(0.219-0.574)$ \\
\hline \multicolumn{5}{|l|}{ Gender } \\
\hline Women & 0.541 & $(0.449-0.635)$ & 0.564 & $(0.372-0.730)$ \\
\hline Men & 0.532 & $(0.457-0.608)$ & 0.530 & $(0.346-0.779)$ \\
\hline \multicolumn{5}{|l|}{ Triage score } \\
\hline Urgent (P3) & 0.489 & $(0.402-0.577)$ & 0.466 & $(0.3 \mid 4-0.660)$ \\
\hline Semi-Urgent (P4) & $0.56 \mathrm{I}$ & $(0.483-0.639)$ & 0.558 & $(0.357-0.783)$ \\
\hline \multicolumn{5}{|l|}{ Gross income, \$CAN } \\
\hline $1-49,999$ & 0.578 & $(0.504-0.652)$ & 0.606 & $(0.437-0.782)$ \\
\hline $50,000-99,999$ & 0.503 & $(0.391-0.616)$ & 0.452 & $(0.317-0.769)$ \\
\hline \multicolumn{5}{|c|}{ Self-reported other health conditions } \\
\hline No & 0.570 & $(0.489-0.650)$ & 0.616 & $(0.357-0.783)$ \\
\hline Yes & 0.492 & $(0.409-0.575)$ & 0.474 & $(0.357-0.622)$ \\
\hline \multicolumn{5}{|l|}{ Onset of MSKD, weeks } \\
\hline $0-2$ & 0.538 & $(0.473-0.604)$ & 0.531 & $(0.366-0.776)$ \\
\hline$>3$ & 0.472 & $(0.342-0.603)$ & 0.462 & $(0.254-0.637)$ \\
\hline \multicolumn{5}{|l|}{ Presenting complaint } \\
\hline Upper limb & 0.626 & $(0.467-0.784)$ & 0.623 & $(0.455-0.784)$ \\
\hline Lower limb & 0.470 & $(0.388-0.553)$ & 0.437 & $(0.328-0.6 \mathrm{II})$ \\
\hline Cervical spine & 0.602 & $(0.469-0.736)$ & 0.656 & $(0.426-0.743)$ \\
\hline Thoracic and lumbar spine & 0.496 & $(0.354-0.638)$ & 0.477 & $(0.254-0.763)$ \\
\hline \multicolumn{5}{|l|}{ Pain intensity, /10 } \\
\hline$<4$ & $0.741^{\mathrm{a}}$ & $(0.50 \mathrm{I}-0.980)$ & $0.867^{\mathrm{a}}$ & $(0.610-0.882)$ \\
\hline 4 to 7 & 0.572 & $(0.500-0.644)$ & 0.616 & $(0.402-0.744)$ \\
\hline$>7$ & 0.433 & $(0.347-0.518)$ & 0.437 & $(0.257-0.549)$ \\
\hline \multicolumn{5}{|c|}{ Pain interference on function, / 10} \\
\hline$<4$ & $0.685^{b}$ & $(0.605-0.764)$ & $0.753^{b}$ & $(0.532-0.862)$ \\
\hline 4 to 7 & 0.463 & $(0.394-0.533)$ & 0.450 & $(0.336-0.612)$ \\
\hline$>7$ & 0.294 & $(0.126-0.463)$ & 0.321 & $(0.1 \mid 9-0.431)$ \\
\hline
\end{tabular}

Notes: ${ }^{a}$ Significant difference between all three pain intensity levels $(p<0.05)$. ${ }^{b}$ Significant difference between all three pain interference levels $(p \leq .00 \mathrm{I})$. Abbreviations: $\mathrm{Cl}$, confidence interval; IQR, interquartile range; MSKD, musculoskeletal disorder.

a serious health problem or having the perception of being in poorer health, would also influence the use of the ED for patients with MSKDs. ${ }^{61}$ In comparing our results with those of the studies by Poder et al, ${ }^{40,60}$ it should be noted that our sample included fewer women and had a lower average income level than those of the population of Quebec. Nevertheless, the two samples were similar in terms of distribution of the age groups surveyed.

In our study, health-related quality of life appeared to be influenced only by higher levels of pain and pain interference on function. These results somewhat contradict those in the literature, in that some studies have shown that socio-demographic characteristics such as age, gender, and income level might influence health-related quality of 


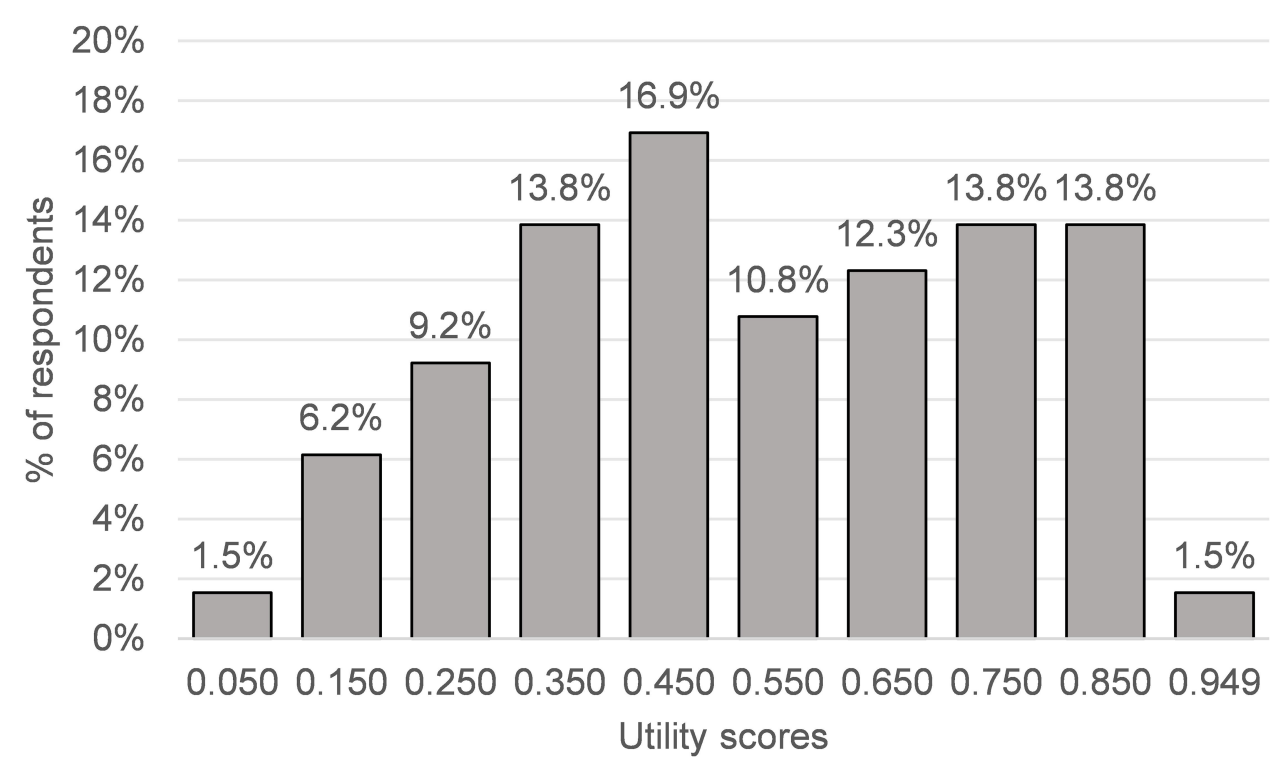

Figure 2 Utility scores distribution for EQ-5D-5L. The utility scores on the $x$-axis represent the central value of each band. The first band is from 0.000 to 0.100 ( 0.050 for the central value) and the last band corresponds to the ceiling effect (0.949).

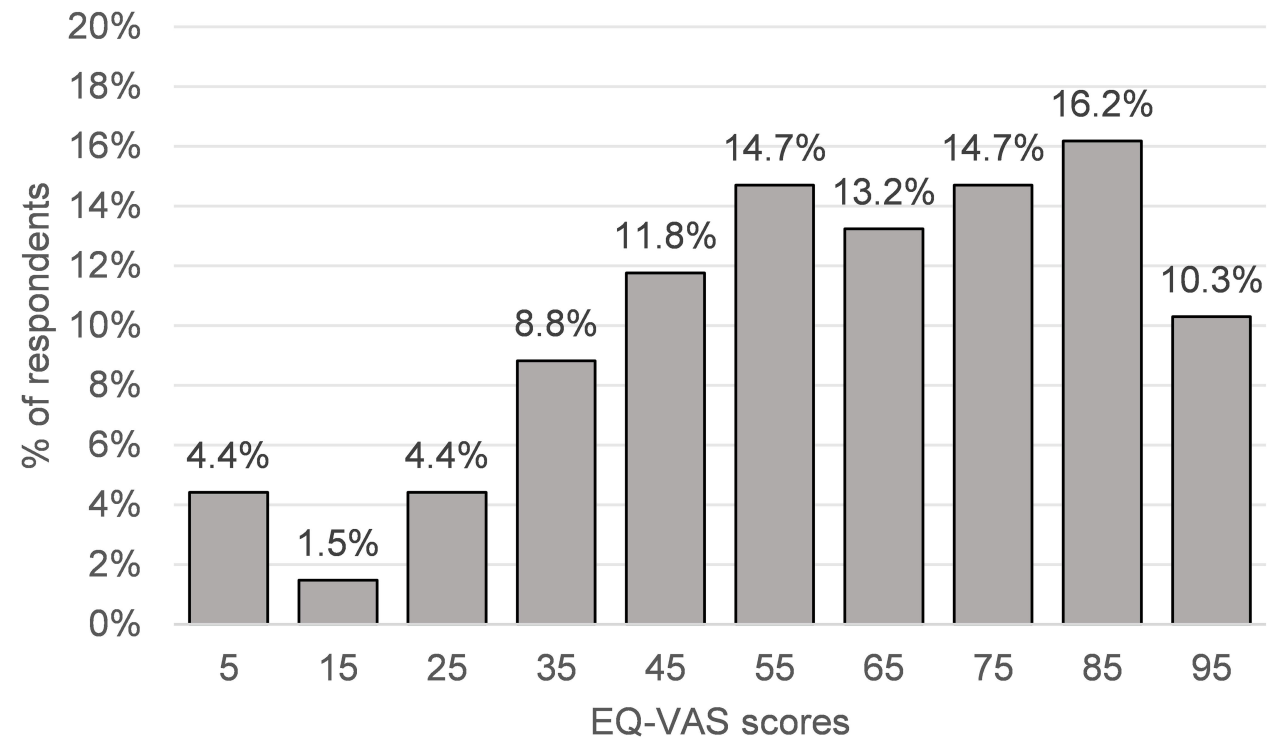

Figure 3 EQ-VAS scores distribution. The EQ-VAS scores on the $\mathrm{x}$-axis represent the central value of each band. The first band is from 0 to 10 ( 5 for the central value) and the last band is from 90 to 100 ( 95 for the central value).

life. ${ }^{40,62}$ However, these results, except for certain results reported by Poder et al, ${ }^{40,60}$ are from healthy participants, not from people presenting with a MSKD. Indeed, although MSKDs affect $20 \%$ to $33 \%$ of the world's population and cost the healthcare system several billion dollars annually, ${ }^{63}$ very few studies have looked at the factors influencing healthrelated quality of life in this sub-population specifically. Those that have done so often focus on a specific disorder (eg, arthritis, scoliosis, total joint replacement, etc.), and not on a sample with a set of disorders representative of this population. ${ }^{64-67}$ Due to the limited data in the literature and the cross-sectional design of our study, a cause-effect relationship regarding the influence of pain intensity and pain interference on health-related quality of life still remains a hypothesis that needs to be verified. Considering the very high prevalence of MSKDs and the expected increase in the number of seniors in the next decade, ${ }^{3}$ a better understanding of factors impacting on health-related quality of life would help better manage patients with MSKDs and ED managers to better tailor ED services and resources to these patients. 
Table 3 Distribution of Problems Reported by Dimension and Demographic Characteristics $(n=69)$

\begin{tabular}{|c|c|c|c|c|c|c|c|c|c|c|c|c|}
\hline & Total & $95 \% \mathrm{Cl}$ & Women & $95 \% \mathrm{Cl}$ & Men & $95 \% \mathrm{Cl}$ & \multirow[t]{2}{*}{ p-value } & Triage Score 3 & $95 \% \mathrm{Cl}$ & Triage Score 4 & $95 \% \mathrm{Cl}$ & \multirow[t]{2}{*}{ p-value } \\
\hline & $n=69$ & (\%) & $n=29$ & (\%) & $n=40$ & (\%) & & $n=29$ & (\%) & $n=39$ & (\%) & \\
\hline $\begin{array}{l}\text { Mobility, \% } \\
\text { No problem } \\
\text { Slight problems } \\
\text { Moderate problems } \\
\text { Severe problems } \\
\text { Unable }\end{array}$ & $\begin{array}{l}27.5 \\
13.0 \\
21.7 \\
24.6 \\
13.0\end{array}$ & $\begin{array}{c}18.4-39.0 \\
7.0-23.0 \\
13.6-32.8 \\
16.0-36.0 \\
7.0-23.0\end{array}$ & $\begin{array}{l}27.6 \\
10.3 \\
31.0 \\
13.8 \\
17.2\end{array}$ & $\begin{array}{c}14.7-45.7 \\
3.6-26.4 \\
17.3-49.2 \\
5.5-30.6 \\
7.6-34.5\end{array}$ & $\begin{array}{l}27.5 \\
15.0 \\
15.0 \\
32.5 \\
10.0\end{array}$ & $\begin{array}{c}16.1-42.8 \\
7.1-29.1 \\
7.1-29.1 \\
20.1-48.0 \\
4.0-23.1\end{array}$ & 0.271 & $\begin{array}{l}13.8 \\
24.1 \\
27.6 \\
17.2 \\
17.2\end{array}$ & $\begin{array}{c}5.5-30.6 \\
12.2-42.1 \\
14.7-45.7 \\
7.6-34.5 \\
7.6-34.5\end{array}$ & $\begin{array}{c}35.9 \\
5.1 \\
17.9 \\
30.8 \\
10.3\end{array}$ & $\begin{array}{c}22.7-51.6 \\
1.4-16.9 \\
9.0-32.7 \\
18.6-46.4 \\
4.1-23.6\end{array}$ & 0.086 \\
\hline $\begin{array}{l}\text { Self-care, \% } \\
\text { No problem } \\
\text { Slight problems } \\
\text { Moderate problems } \\
\text { Severe problems } \\
\text { Unable }\end{array}$ & $\begin{array}{c}42.0 \\
20.3 \\
29.0 \\
7.2 \\
1.4\end{array}$ & $\begin{array}{c}31.1-53.8 \\
12.5-31.2 \\
19.6-40.6 \\
3.1-15.9 \\
0.3-7.8\end{array}$ & $\begin{array}{c}41.4 \\
13.8 \\
34.5 \\
6.9 \\
3.4\end{array}$ & $\begin{array}{c}25.5-59.3 \\
5.5-30.6 \\
19.9-52.7 \\
1.9-22.0 \\
0.6-17.2\end{array}$ & $\begin{array}{c}42.5 \\
25.0 \\
25.0 \\
7.5 \\
0.0\end{array}$ & $\begin{array}{c}28.5-57.8 \\
14.2-40.2 \\
14.2-40.2 \\
2.6-19.9 \\
-\end{array}$ & 0.604 & $\begin{array}{c}27.6 \\
31.0 \\
27.6 \\
10.3 \\
3.4\end{array}$ & $\begin{array}{c}14.7-45.7 \\
17.3-49.2 \\
14.7-45.7 \\
3.6-26.4 \\
0.6-17.2\end{array}$ & $\begin{array}{c}51.3 \\
12.8 \\
30.8 \\
5.1 \\
0.0\end{array}$ & $\begin{array}{c}36.2-66.1 \\
5.6-26.7 \\
18.6-46.4 \\
1.4-16.9 \\
-\end{array}$ & 0.266 \\
\hline $\begin{array}{l}\text { Usual Activities, \% } \\
\text { No problem } \\
\text { Slight problems } \\
\text { Moderate problems } \\
\text { Severe problems } \\
\text { Unable }\end{array}$ & $\begin{array}{c}n=68 \\
10.3 \\
19.1 \\
33.8 \\
27.9 \\
8.8\end{array}$ & $\begin{array}{c}5.1-19.8 \\
11.5-30.0 \\
23.7-45.7 \\
18.7-39.6 \\
4.1-17.9\end{array}$ & $\begin{array}{l}13.8 \\
27.6 \\
31.0 \\
17.2 \\
10.3\end{array}$ & $\begin{array}{c}5.4-30.6 \\
14.7-45.7 \\
17.3-49.2 \\
7.6-34.5 \\
3.6-26.4\end{array}$ & $\begin{array}{l}n=39 \\
7.7 \\
12.8 \\
35.9 \\
35.9 \\
7.7\end{array}$ & $\begin{array}{c}2.7-20.3 \\
5.6-26.7 \\
22.7-51.6 \\
22.7-51.6 \\
2.7-20.3\end{array}$ & 0.327 & $\begin{array}{l}n=28 \\
7.1 \\
14.3 \\
28.6 \\
35.7 \\
14.3\end{array}$ & $\begin{array}{c}2.0-22.6 \\
5.7-31.5 \\
\mid 5.3-47.1 \\
20.7-54.2 \\
5.7-31.5\end{array}$ & $\begin{array}{c}12.8 \\
20.5 \\
38.5 \\
23.1 \\
5.1\end{array}$ & $\begin{array}{c}5.6-26.7 \\
10.8-35.5 \\
24.9-54.1 \\
12.6-38.3 \\
1.4-16.9\end{array}$ & 0.418 \\
\hline $\begin{array}{l}\text { Pain/Discomfort, \% } \\
\text { No } \\
\text { Slight } \\
\text { Moderate } \\
\text { Severe } \\
\text { Extreme }\end{array}$ & $\begin{array}{c}n=66 \\
3.0 \\
13.6 \\
34.8 \\
45.5 \\
3.0\end{array}$ & $\begin{array}{c}0.8-10.4 \\
7.3-23.9 \\
24.5-46.9 \\
34.0-57.4 \\
0.8-10.4\end{array}$ & $\begin{array}{l}n=28 \\
7.1 \\
14.3 \\
35.7 \\
39.3 \\
3.6\end{array}$ & $\begin{array}{c}2.0-22.6 \\
5.7-31.5 \\
20.7-54.2 \\
23.6-57.6 \\
0.6-17.7\end{array}$ & $\begin{array}{l}n=38 \\
0.0 \\
13.2 \\
34.2 \\
50.0 \\
2.6\end{array}$ & $\begin{array}{c}- \\
5.8-27.3 \\
21.2-50.1 \\
34.8-65.2 \\
0.5-13.5\end{array}$ & 0.600 & $\begin{array}{c}\mathrm{n}=28 \\
3.6 \\
10.7 \\
32.1 \\
50.0 \\
3.6\end{array}$ & $\begin{array}{c}0.6-17.7 \\
3.7-27.2 \\
17.9-50.7 \\
32.6-67.4 \\
0.6-17.7\end{array}$ & $\begin{array}{c}\mathrm{n}=37 \\
2.7 \\
13.5 \\
37.8 \\
43.2 \\
2.7\end{array}$ & $\begin{array}{c}0.5-13.8 \\
5.9-28.0 \\
24.1-53.9 \\
28.7-59.1 \\
0.5-13.8\end{array}$ & 0.398 \\
\hline $\begin{array}{l}\text { Anxiety/Depression, \% } \\
\text { No } \\
\text { Slight } \\
\text { Moderate } \\
\text { Severe } \\
\text { Extreme }\end{array}$ & $\begin{array}{l}53.6 \\
27.5 \\
14.5 \\
2.9 \\
1.4\end{array}$ & $\begin{array}{c}42.0-64.9 \\
18.4-39.0 \\
8.1-24.7 \\
0.8-10.0 \\
0.3-7.8\end{array}$ & \begin{tabular}{c|}
48.3 \\
27.6 \\
17.2 \\
3.4 \\
3.4
\end{tabular} & $\begin{array}{c}31.4-65.6 \\
14.7-45.7 \\
7.6-34.5 \\
0.6-17.2 \\
0.6-17.2\end{array}$ & $\begin{array}{c}57.5 \\
27.5 \\
12.5 \\
2.5 \\
0.0\end{array}$ & $\begin{array}{c}42.2-7 \mid .5 \\
\mid 6.1-42.8 \\
5.5-26.1 \\
0.4-12.9 \\
-\end{array}$ & 0.834 & $\begin{array}{l}48.3 \\
31.0 \\
17.2 \\
3.4 \\
0.0\end{array}$ & $\begin{array}{c}31.4-65.6 \\
17.3-49.2 \\
7.6-34.5 \\
0.6-17.2 \\
-\end{array}$ & $\begin{array}{c}56.4 \\
25.6 \\
12.8 \\
2.6 \\
2.6\end{array}$ & $\begin{array}{c}41.0-70.7 \\
|4.6-4| . \mid \\
5.6-26.7 \\
0.5-13.2 \\
0.5-13.2\end{array}$ & 0.960 \\
\hline
\end{tabular}


To our knowledge, our study is the first to report utility scores in a sample of patients presenting to the ED for a MSKD in Quebec (Canada) and, more broadly, in North America. Another strength of our study is that we analyzed socio-demographic and clinical factors that may potentially influence health-related quality of life.

Nevertheless, our results should be interpreted with caution. Our sample size was small; so, some of the subcategories presented have relatively few participants. Studies with larger sample size will be required to confirm our results. We used a subpopulation of patients with the disorder and not a representative sample of the population presented with the disorder. However, having asked for scores from patients with MSKDs in the ED also provides a better representation of the wide variability of symptoms that can present in the ED. Finally, our sample should have contained more participants aged 65 and over to be more representative of the general population and to allow for more in-depth analyses of this subgroup of interest. Still, several studies conducted in the ED among people with MSKDs report average ages similar to our own. ${ }^{15,16,68}$ It is therefore reasonable to believe that our sample remains representative of the population consulting the ED for a MSKD.

\section{Conclusion}

In MSKD patients presenting to the ED, health-related utility scores are lower than the Quebec population reference values and higher levels of pain or pain interference are associated with decreased health-related quality of life. These findings need to be confirmed using multicentre studies with a larger sample size.

\section{Abbreviations}

MSKDs, musculoskeletal disorders; ED, emergency department; VAS, visual analog scale; Yrs, years; CI, confidence interval; IQR, interquartile range; MID, minimally important difference.

\section{Data Sharing Statement}

The datasets analyzed during the current study are available from the corresponding author on reasonable request.

\section{Ethics Approval and Informed Consent}

The study was conducted according to the guidelines of the Declaration of Helsinki, and approved by the Ethics Committee of the CHU de Québec - Université Laval (\#MP-20-2019-4307, 2018-20-08). Informed consent was obtained from all subjects involved in the study.

\section{Acknowledgments}

We would like to thank the following persons for their contribution to project implementation: All project participants, Antony Barabé, PT, physiotherapist at the Centre Hospitalier de l'Université Laval (CHUL), the entire team of managers at the Direction des services multidisciplinaires of the CHU de Québec - Université Laval (Marie-Christine Laroche, Catherine van Neste, Marie-Claude Brodeur and Stéphane Tremblay) for their support throughout the implementation of the project and its realization, and Mathieu Blanchet, MD, FRCPC, head of the CHUL ED department during the duration of the study.

\section{Author Contributions}

All authors made a significant contribution to the work reported, whether that is in the conception, study design, execution, acquisition of data, analysis and interpretation, or in all these areas; took part in drafting, revising or critically reviewing the article; gave final approval of the version to be published; have agreed on the journal to which the article has been submitted; and agree to be accountable for all aspects of the work.

\section{Funding}

This research was funded by the CHU de Québec - Université Laval, subsidies from L.J.H. and K.P. and a research grant awarded by the Fondation du CHU de Québec for the multidisciplinary council of the CHU de Québec - Université Laval. R.G. received scholarships from the Canadian Institutes of Health Research, the Cirris, the Ordre professionnel de 
la physiothérapie du Québec and the Department of Rehabilitation funds of the Faculty of Medicine at Université Laval. K.P. and J.R.G. are Fonds de recherche du Québec-Santé (FRSQ) Junior 1 Research Scholars.

\section{Disclosure}

The authors declare no competing interests.

\section{References}

1. Ledoux E, Denis D. Enquête québécoise sur des conditions de travail, d'emploi et de santé et de sécurité du travail (EQCOTESST). [Quebec survey on working conditions, employment and occupational health and safety (EQCOTESST)]. Perspectives interdisciplinaires sur le travail et la santé. 2011;(13-12). doi:10.4000/pistes.1831.French.

2. Agel J, Akesson K, Amadio PC, Anderson M, Rasker JJ. The burden of musculoskeletal conditions at the start of the new millennium; 2003. Available from: https://research.utwente.nl/en/publications/the-burden-of-musculoskeletal-conditions-at-the-start-of-the-new-millenium. Accessed June 28, 2019.

3. Institute of Musculoskeletal Health and Arthritis (Canada), Canadian Institutes of Health Research. Institute of musculoskeletal health and arthritis strategic plan 2014-2018: enhancing musculoskeletal, skin and oral health; 2014. Available from: https://central.bac-lac.gc.ca/.item?id=MR4-352014-eng $\oplus$ pdf\&app=Library. Accessed January 10, 2020.

4. The Big Picture. BMUS: the burden of musculoskeletal diseases in the United States. Available from: https://www.boneandjointburden.org/fourthedition/i1/big-picture. Accessed January 10, 2020.

5. Bhattacharya A. Costs of occupational musculoskeletal disorders (MSDs) in the United States. Int J Ind Ergon. 2014;44(3):448-454. doi:10.1016/j. ergon.2014.01.008

6. Wand BM, Bird C, McAuley JH, Doré CJ, MacDowell M, De Souza LH. Early intervention for the management of acute low back pain: a single-blind randomized controlled trial of biopsychosocial education, manual therapy, and exercise. Spine. 2004;29(21):2350-2356. doi:10.1097/ 01.brs.0000143619.34308.b4

7. Rosenfeld M, Gunnarsson R, Borenstein P. Early intervention in whiplash-associated disorders: a comparison of two treatment protocols. Spine. 2000;25(14):1782-1787. doi:10.1097/00007632-200007150-00008

8. Horn ME, Brennan GP, George SZ, Harman JS, Bishop MD. A value proposition for early physical therapist management of neck pain: a retrospective cohort analysis. BMC Health Serv Res. 2016;16. doi:10.1186/s12913-016-1504-5

9. Childs JD, Fritz JM, Wu SS, et al. Implications of early and guideline adherent physical therapy for low back pain on utilization and costs. $B M C$ Health Serv Res. 2015;15:150. doi:10.1186/s12913-015-0830-3

10. Ehrmann-Feldman D, Rossignol M, Abenhaim L, Gobeille D. Physician referral to physical therapy in a cohort of workers compensated for low back pain. Phys Ther. 1996;76(2):150-156. doi:10.1093/ptj/76.2.150

11. Fritz JM, Childs JD, Wainner RS, Flynn TW. Primary care referral of patients with low back pain to physical therapy: impact on future health care utilization and costs. Spine. 2012;37(25):2114-2121. doi:10.1097/BRS.0b013e31825d32f5

12. Gellhorn AC, Chan L, Martin B, Friedly J. Management patterns in acute low back pain: the role of physical therapy. Spine (Phila Pa 1976). 2012;37(9):775-782. doi:10.1097/BRS.0b013e3181d79a09

13. Kucera KL, Lipscomb HJ, Silverstein B. Medical care surrounding work-related back injury claims among Washington State Union Carpenters, 1989-2003. Work. 2011;39(3):321-330. doi:10.3233/WOR-2011-1180

14. Zigenfus GC, Yin J, Giang GM, Fogarty WT. Effectiveness of early physical therapy in the treatment of acute low back musculoskeletal disorders. J Occup Environ Med. 2000;42(1):35. doi:10.1097/00043764-200001000-00010

15. Bird S, Thompson C, Williams KE. Primary contact physiotherapy services reduce waiting and treatment times for patients presenting with musculoskeletal conditions in Australian emergency departments: an observational study. J Physiother. 2016;62(4):209-214. doi:10.1016/j. jphys.2016.08.005

16. de Gruchy A, Granger C, Gorelik A. Physical therapists as primary practitioners in the emergency department: six-month prospective practice analysis. Phys Ther. 2015;95(9):1207. doi:10.2522/ptj.20130552

17. Gaieski DF, Mehta S, Hollander JE, Shofer F, Bernstein J. Low-severity musculoskeletal complaints evaluated in the emergency department. Clin Orthop Relat Res. 2008;466(8):1987-1995. doi:10.1007/s11999-008-0277-5

18. Idil H, Kilic TY, Toker İ, Dura Turan K, Yesilaras M. Non-urgent adult patients in the emergency department: causes and patient characteristics. Turk J Emerg Med. 2018;18(2):71-74. doi:10.1016/j.tjem.2017.10.002

19. CHU de Québec - Université Laval. Portfolio des Services d'Urgence 2014-2015 - Clientèle par catégorie majeure de diagnostic (CMD). [Portfolio of Emergency Services 2014-2015 - Clientele by Major Diagnosis Category]. 2015. French.

20. Nordeman L, Nilsson B, Möller M, Gunnarsson R. Early access to physical therapy treatment for subacute low back pain in primary health care: a prospective randomized clinical trial. Clin J Pain. 2006;22(6):505-511. doi:10.1097/01.ajp.0000210696.46250.0d

21. Rundell SD, Gellhorn AC, Comstock BA, Heagerty P, Friedly JL, Jarvik JG. Clinical outcomes of early and later physical therapist services for older adults with back pain. Spine J. 2015;15(8):1744-1755. doi:10.1016/j.spinee.2015.04.001

22. Branco JC, Rodrigues AM, Gouveia N, et al. Prevalence of rheumatic and musculoskeletal diseases and their impact on health-related quality of life, physical function and mental health in Portugal: results from EpiReumaPt- a national health survey. RMD Open. 2016;2(1):e00166. doi:10.1136/rmdopen-2015-000166

23. Picavet HSJ, Hoeymans N. Health related quality of life in multiple musculoskeletal diseases: SF-36 and EQ-5D in the DMC3 study. Ann Rheum Dis. 2004;63(6):723-729. doi:10.1136/ard.2003.010769

24. Paananen M, Taimela S, Auvinen J, Tammelin T, Zitting P, Karppinen J. Impact of self-reported musculoskeletal pain on health-related quality of life among young adults. Pain Med. 2011;12(1):9-17. doi:10.1111/j.1526-4637.2010.01029.x

25. Kempen GI, Ormel J, Brilman EI, Relyveld J. Adaptive responses among Dutch elderly: the impact of eight chronic medical conditions on health-related quality of life. Am J Public Health. 1997;87(1):38-44. doi:10.2105/AJPH.87.1.38 
26. Sprangers MAG, de Regt EB, Andries F, et al. Which chronic conditions are associated with better or poorer quality of life? J Clin Epidemiol. 2000;53(9):895-907. doi:10.1016/S0895-4356(00)00204-3

27. Stafford V, Greenhalgh S, Davidson I. Why do patients with simple mechanical back pain seek urgent care? Physiotherapy. 2014;100(1):66-72. doi:10.1016/j.physio.2013.08.001

28. Guengerich M, Brock K, Cotton S, Mancuso S. Emergency department primary contact physiotherapists improve patient flow for musculoskeletal patients. Int J Ther Rehabil. 2013;20(8):396-402. doi:10.12968/ijtr.2013.20.8.396

29. Jesudason C, Stiller K, McInnes M, Sullivan T. A physiotherapy service to an emergency extended care unit does not decrease admission rates to hospital: a randomised trial. Emerg Med J. 2012;29(8):664-669. doi:10.1136/emermed-2011-200157

30. Kinsella R, Collins T, Shaw B, et al. Management of patients brought in by ambulance to the emergency department: role of the advanced musculoskeletal physiotherapist. Aust Health Rev. 2017. doi:10.1071/AH16094

31. Lau PMY, Chow DHK, Pope MH. Early physiotherapy intervention in an accident and emergency department reduces pain and improves satisfaction for patients with acute low back pain: a randomised trial. Austr J Physiother. 2008;54(4):243-249. doi:10.1016/S0004-9514(08) 70003-5

32. McClellan CM, Greenwood R, Benger JR. Effect of an extended scope physiotherapy service on patient satisfaction and the outcome of soft tissue injuries in an adult emergency department. Emerg Med J. 2006;23(5):384-387. doi:10.1136/emj.2005.029231

33. Morris J, Vine K, Grimmer K. Evaluation of performance quality of an advanced scope physiotherapy role in a hospital emergency department. Patient Relat Outcome Meas. 2015;6:191-203. doi:10.2147/PROM.S75173

34. Schulz P, Prescott J, Shifman J, Fiore J, Holland A, Harding P. Comparing patient outcomes for care delivered by advanced musculoskeletal physiotherapists with other health professionals in the emergency department-A pilot study. Australas Emerg Nurs J. 2016;19(4):198-202. doi:10.1016/j.aenj.2016.06.001

35. Sutton M, Govier A, Prince S, Morphett M. Primary-contact physiotherapists manage a minor trauma caseload in the emergency department without misdiagnoses or adverse events: an observational study. J Physiother. 2015;61(2):77-80. doi:10.1016/j.jphys.2015.02.012

36. Taylor NF, Norman E, Roddy L, Tang C, Pagram A, Hearn K. Primary contact physiotherapy in emergency departments can reduce length of stay for patients with peripheral musculoskeletal injuries compared with secondary contact physiotherapy: a prospective non-randomised controlled trial. Physiotherapy. 2011;97(2):107-114. doi:10.1016/j.physio.2010.08.011

37. Feng YS, Kohlmann T, Janssen MF, Buchholz I. Psychometric properties of the EQ-5D-5L: a systematic review of the literature. Qual Life Res. 2021;30(3):647-673. doi:10.1007/s11136-020-02688-y

38. Xie F, Pullenayegum E, Gaebel K, et al. A time trade-off-derived value set of the EQ-5D-5L for Canada. Med Care. 2016;54(1):98-105. doi:10.1097/MLR.0000000000000447

39. Ferreira LN, Ferreira PL, Pereira LN, Oppe M. EQ-5D Portuguese population norms. Qual Life Res. 2014;23(2):425-430. doi:10.1007/s11136-013$0488-4$

40. Poder TG, Carrier N, Kouakou CRC. Quebec health-related quality-of-life population norms using the EQ-5D-5L: decomposition by sociodemographic data and health problems. Value Health. 2020;23(2):251-259. doi:10.1016/j.jval.2019.08.008

41. van den Berg B. Sf-6d population norms. Health Econ. 2012;21(12):1508-1512. doi:10.1002/hec.1823

42. Ferreira PL, Ferreira LN, Pereira LN. SF-6D Portuguese population norms. Eur J Health Econ. 2015;16(3):235-241. doi:10.1007/s10198-0140568-6

43. Williams A. Calculating the global burden of disease: time for a strategic reappraisal? Health Econ. 1999;8(1):1-8. doi:10.1002/(sici)10991050(199902)8:1<1::aid-hec399>3.0.co;2-b

44. Naseer M, Dahlberg L, Fagerström C. Health related quality of life and emergency department visits in adults of age $\geq 66$ years: a prospective cohort study. Health Qual Life Outcomes. 2018;16(1):144. doi:10.1186/s12955-018-0967-y

45. Saarni SI, Suvisaari J, Sintonen H, Koskinen S, Härkänen T, Lönnqvist J. The health-related quality-of-life impact of chronic conditions varied with age in general population. J Clin Epidemiol. 2007;60(12):1288.e1-1288.e11. doi:10.1016/j.jclinepi.2007.03.004

46. Bingefors K, Isacson D. Epidemiology, co-morbidity, and impact on health-related quality of life of self-reported headache and musculoskeletal pain - a gender perspective. Eur J Pain. 2004;8(5):435-450. doi:10.1016/j.ejpain.2004.01.005

47. López L, Wilper AP, Cervantes MC, Betancourt JR, Green AR. Racial and sex differences in emergency department triage assessment and test ordering for chest pain, 1997-2006. Acad Emerg Med. 2010;17(8):801-808. doi:10.1111/j.1553-2712.2010.00823.x

48. Magnusson C, Herlitz J, Axelsson C. Patient characteristics, triage utilisation, level of care, and outcomes in an unselected adult patient population seen by the emergency medical services: a prospective observational study. BMC Emerg Med. 2020;20(1):7. doi:10.1186/s12873-020-0302-x

49. Gerdtz MF, Weiland TJ, Jelinek GA, Mackinlay C, Hill N. Perspectives of emergency department staff on the triage of mental health-related presentations: implications for education, policy and practice. Emerg Med Austral. 2012;24(5):492-500. doi:10.1111/j.1742-6723.2012.01592.x

50. Gagnon R, Perreault K, Berthelot S, et al. Direct-access physiotherapy to help manage patients with musculoskeletal disorders in an emergency department: results of a randomized controlled trial. Acad Emerg Med. 2021;28(8):848-858. doi:10.1111/acem.14237

51. Beveridge R, Clarke B, Janes L, et al. L'échelle canadienne de triage \& de gravité pour les départements d'urgence Guide d'implantation. [The Canadian Triage and Acuity Scale for Emergency Departments Implementation Guide]. Can J Emerg Med. 1999;1(3). Available from: https://www. colleaga.org/sites/default/files/ctased16.pdf. Accessed February 09, 2022. French.

52. EQ-5D-5L - EQ-5D. Available from: https://euroqol.org/eq-5d-instruments/eq-5d-51-about/. Accessed August 27, 2020.

53. Bilbao A, García-Pérez L, Arenaza JC, et al. Psychometric properties of the EQ-5D-5L in patients with hip or knee osteoarthritis: reliability, validity and responsiveness. Qual Life Res. 2018;27(11):2897-2908. doi:10.1007/s11136-018-1929-x

54. Conner-Spady BL, Marshall DA, Bohm E, et al. Reliability and validity of the EQ-5D-5L compared to the EQ-5D-3L in patients with osteoarthritis referred for hip and knee replacement. Qual Life Res. 2015;24(7):1775-1784. doi:10.1007/s11136-014-0910-6

55. Jensen MP, McFarland CA. Increasing the reliability and validity of pain intensity measurement in chronic pain patients. Pain. 1993;55(2):195-203. doi:10.1016/0304-3959(93)90148-I

56. Bijur PE, Latimer CT, Gallagher EJ. Validation of a verbally administered numerical rating scale of acute pain for use in the emergency department. Acad Emerg Med. 2003;10(4):390-392. doi:10.1111/j.1553-2712.2003.tb01355.x

57. Michener LA, Snyder AR, Leggin BG. Responsiveness of the numeric pain rating scale in patients with shoulder pain and the effect of surgical status. J Sport Rehabil. 2011;20(1):115-128. doi:10.1123/jsr.20.1.115 
58. Mendoza T, Mayne T, Rublee D, Cleeland C. Reliability and validity of a modified Brief Pain Inventory short form in patients with osteoarthritis. Eur J Pain. 2006;10(4):353. doi:10.1016/j.ejpain.2005.06.002

59. Walters SJ, Brazier JE. Comparison of the minimally important difference for two health state utility measures: EQ-5D and SF-6D. Qual Life Res. 2005;14(6):1523-1532. doi:10.1007/s11136-004-7713-0

60. Poder TG, Wang L, Carrier N. EQ-5D-5L and SF-6Dv2 utility scores in people living with chronic low back pain: a survey from Quebec. $B M J$ Open. 2020;10(9):e035722. doi:10.1136/bmjopen-2019-035722

61. Roberge D, Larouche D, Pineault R. L'urgence hospitalière: un substitut à la première ligne? Résultats d'une enquête auprès de la population de Montréal et de la Montérégie. [Hospital emergency: a substitute for primary care? Results of a survey of the population of Montreal and Montérégie]. 2007:12. French.

62. Grochtdreis T, Dams J, König HH, Konnopka A. Health-related quality of life measured with the EQ-5D-5L: estimation of normative index values based on a representative German population sample and value set. Eur J Health Econ. 2019;20(6):933-944. doi:10.1007/s10198-01901054-1

63. World Health Organization (WHO). Musculoskeletal conditions. Available from: https://www.who.int/news-room/fact-sheets/detail/musculoskele tal-conditions. Accessed February 15, 2021.

64. Diarbakerli E, Grauers A, Danielsson A, Gerdhem P. Health-related quality of life in adulthood in untreated and treated individuals with adolescent or juvenile idiopathic scoliosis. J Bone Joint Surg. 2018;100(10):811-817. doi:10.2106/JBJS.17.00822

65. Diarbakerli E, Grauers A, Danielsson A, Abbott A, Gerdhem P. Quality of life in males and females with idiopathic scoliosis. Spine. 2019;44 (6):404-410. doi:10.1097/BRS.000000000002857

66. Miao NF, Lin PC. A prospective study of joint function and the quality of life of patients undergoing total joint replacement. Int J Nurs Pract. 2018;24(5):e12675. doi:10.1111/ijn.12675

67. Xavier RM, Zerbini CAF, Pollak DF, et al. Burden of rheumatoid arthritis on patients' work productivity and quality of life. Adv Rheumatol. 2019;59(1):47. doi:10.1186/s42358-019-0090-8

68. Sohil P, Hao PY, Mark L. Potential impact of early physiotherapy in the emergency department for non-traumatic neck and back pain. World $J$ Emerg Med. 2017;8(2):110-115. doi:10.5847/wjem.j.1920-8642.2017.02.005

ClinicoEconomics and Outcomes Research

\section{Publish your work in this journal}

ClinicoEconomics and Outcomes Research is an international, peer-reviewed open-access journal focusing on Health Technology Assessment, Pharmacoeconomics and Outcomes Research in the areas of diagnosis, medical devices, and clinical, surgical and pharmacological intervention. The economic impact of health policy and health systems organization also constitute important areas of coverage. The manuscript management system is completely online and includes a very quick and fair peer-review system, which is all easy to use. Visit http://www.dovepress.com/testimonials.php to read real quotes from published authors.

Submit your manuscript here: https://www.dovepress.com/clinicoeconomics-and-outcomes-research-journal 